\title{
Descentralização e gestão do ensino nos programas PDE \\ Escola e Mais Educação
}

\author{
Descentralization and education management in the programs PDE \\ School and More Education \\ Descentralización y gestión de la educación en los programas PDE \\ Escuela y Más Educación \\ RITA DE CÁSSIA OLIVEIRA \\ BEATRIZ DE BASTO TEIXEIRA
}

\begin{abstract}
Resumo: $\mathrm{O}$ artigo tem origem em tese de doutorado e apresenta efeitos dos programas PDE Escola e Mais Educação na gestão de escolas e da rede de ensino a que estas se vinculam. A adesão aos programas ampliou a possibilidade de melhoria da qualidade de ensino, o que é seu objetivo, ao mesmo tempo em que trouxe desafios para a gestão escolar. A associação de tais programas à descentralização financeira da União diretamente às escolas, ainda que em pactuação com o município, criou novas demandas à gestão escolar e à Secretaria de Educação Municipal sem que estivessem prontas a atender.
\end{abstract}

Palavras-chave: Descentralização, qualidade do ensino público, gestão da educação escolar, financiamento da educação.

Abstract: This article comes from a doctoral thesis and presents some effects of the programs PDE School and More Education in school management and in the school system to which they link. The adherence to the programs increased the potential for improving the quality of education, which is its aim, while it brought challenges for school management. The association of such programs to financial decentralization directly to schools, although to a pact with the municipality, has created new demands on school management and on municipal agency of education, which they were not ready to attend.

Keywords: Decentralization, quality of public education, school management, educational funding.

Resumen: El artículo proviene de tesis doctoral y presenta efectos de los programas "PDE Escuela" y "Más Educación" en la gestión de escuelas y del sistema escolar a que están vinculadas. La adhesión a los programas aumentó las posibilidades de mejorar la calidad de la educación, lo que es su objetivo, si bien trajo desafíos para la gestión de la escuela. La asociación de este tipo de programas a la descentralización financiera directamente a las escuelas, aunque pactuada con el municipio, creó nuevas demandas en la gestión escolar y en la agencia municipal de la educación sin que estaban listos para servir.

Palabras clave: Descentralización, calidad de la educación pública, gestión de escuelas, financiamento de la educación. 


\section{INTRODUÇÃO}

Neste artigo, apresentamos parte dos estudos e dos resultados de pesquisa sobre os efeitos da descentralização realizada por meio de dois programas que integram o Plano de Desenvolvimento da Educação (PDE) ${ }^{1}$ : o Plano de Desenvolvimento da Escola (PDE Escola) ${ }^{2}$ e o Mais Educação (PME). A pesquisa abrangeu, entre 2007 e 2012, a gestão de escolas da rede de ensino a que se vinculavam e dos recursos financeiros destinados ao ensino, alcançando o Conselho Municipal de Educação e, assim, o Sistema de Ensino no município de Juiz de Fora, em Minas Gerais. Contou com contribuições de setores do MEC.

Tais efeitos têm origem na descentralização financeira associada à indução de política educacional da União para as escolas dos entes federativos subnacionais. Esse aspecto foi percebido por meio do estudo da trajetória que a política da União percorreu até chegar às escolas municipais. Inicialmente, esse exame da política ancorou-se sobre a tríade direito educacional, gestão democrática e financiamento da educação, apoiando esses estudos na sua relação com a qualidade do ensino. Não seria possível estudar o direito promulgado, a gestão democrática e o financiamento do ensino sem mobilizar esforços para conectá-los àquilo que é substância do que se pretende alcançar por meio dos recursos materiais e da ação humana.

Em face da complexidade de associar esses estudos mais amplos às investigações nas escolas, houve a necessidade de delimitação amostral. As escolas de Juiz de Fora já recebiam, desde 1995, os recursos financeiros do Programa Dinheiro Direto na Escola (PDDE), do Fundo Nacional de Desenvolvimento da Educação (FNDE), e do Programa Nossa Escola (PNE/SE) da Prefeitura de Juiz de Fora (JUIZ DE FORA, 1995). Após a proposição do PDE, em 2007, as escolas brasileiras com o Índice de Desenvolvimento da Educação Básica $(\mathrm{IDEB})^{3}$ abaixo da meta nacional passaram a poder receber os recursos do PDE Escola e do PME. Por isso, coexistiam nessa mesma rede de ensino, no período pesquisado: a) escolas com o IDEB acima da meta e duas fontes de recursos

O Decreto $\mathrm{n}^{\circ}$ 6094, de 24 de abril de 2007 dispôs sobre o Plano de Metas Compromisso Todos pela Educação e sobre o lançamento do PDE (BRASIL, 2007a), objetivando a melhoria da qualidade do ensino público. O Plano de Desenvolvimento da Educação (PDE) trouxe a possibilidade de adesão a diversas políticas, entre as quais se incluem os programas PDE Escola (BRASIL, 2007c) e PME (BRASIL, 2007b; 2010).

2 O PDE Escola integrava o FUNDESCOLA desde 1998, com a sigla: PDE. Com a criação do Plano de Desenvolvimento da Educação (PDE), em 2007, houve mudança na sigla desse programa, que passou a ser denominado PDE Escola, para que não houvesse equívocos na diferenciação entre o Plano de Desenvolvimento da Educação (PDE) e o Plano de Desenvolvimento da Escola (PDE Escola), que integra o PDE.

3 Como o IDEB é o indicador utilizado como referência para a destinação de recursos às escolas, é também referência para essa organização metodológica. 
financeiros: PNE/SE e o PDDE; b) escolas com o IDEB abaixo dessa meta, também recebendo esse aporte do PNE/SE e do PDDE, além de poder receber financiamento, materiais didático pedagógicos e equipamentos para implementar o PDE Escola e o PME.

Com a coleta dos dados quantitativos, criamos um banco de dados que, conjuntamente com as observações, permitiu a delimitação amostral em acordo com os objetivos da pesquisa: a) uma escola pequena ${ }^{4}$, com oferta da educação em tempo integral, IDEB abaixo da média e, por isso, com a possibilidade de fazer adesão aos dois programas, contando com os aportes financeiros do PDDE, do PNE/SE, do PDE Escola e do PME; b) uma escola de médio porte, com IDEB abaixo da média, sem essa adesão, contou com duas fontes de recursos financeiros: o PDDE e o PNE/ SE; c) uma escola de grande porte, com IDEB acima da média, também sem a adesão aos dois programas, recebeu financiamento dessas duas fontes; e d) uma escola de pequeno porte, com IDEB abaixo da média e adesão ao PDE Escola e ao PME, contou com as quatro fontes de recursos: do PDDE, do PNE/SE, do PDE Escola e do PME.

Nessas escolas, na Secretaria de Educação Municipal e no Conselho Municipal de Educação foram realizadas observações para conhecer dados organizacionais e infraestruturais, análise documental e entrevistas semiestruturadas para interlocução com: diretores, vice-diretores, coordenadores, professores e outros profissionais das escolas; técnicos da Secretaria de Educação Municipal e a Coordenadora Geral de Gestão Educacional, da Diretoria de Currículo e Educação Integral do Ministério da Educação (MEC).

O PDE Escola e o PME tocam diretamente o ensino fundamental, por meio do recebimento não somente de recursos financeiros e materiais, mas também de propostas de mudanças na gestão das escolas e nos currículos nelas praticados. Essa estratégia política da União passa por fora da gestão dos sistemas de ensino para chegar à gestão das suas escolas. Por isso, seus efeitos constituem um dos eixos mais amplos de estudos na pesquisa tratada no limite deste texto.

O PDE Escola foi proposto com o objetivo de melhorar a gestão escolar por meio do planejamento estratégico. No PME, a melhoria da qualidade do ensino é buscada a partir do apoio às atividades socioeducativas no contraturno escolar, tomando como referência destacada o artigo 34 da Lei de Diretrizes e Bases da Educação Nacional (LDBEN) de 1996 (BRASIL, 1996), que determina a progressiva ampliação da jornada escolar.

\footnotetext{
4 Classificamos as 105 escolas do município por seu tamanho, considerando o número de matrículas: pequena - em torno de 300 alunos matriculados; média - em torno de 600 alunos; e grande - em torno de 900 alunos.
} 
Os recursos financeiros tem origem no FNDE e chegam às escolas por meio do PDDE e, após a pactuação entre os governos estaduais e municipais e o MEC, por meio do Plano de Ações Articuladas (PAR). Veremos que, do enlace entre o PDE Escola, o PME e o PDDE derivam uma linha de continuidade e o aprofundamento da descentralização por meio da capilarização das ações nas escolas. Em princípio, trata-se de descentralização sob o argumento de fortalecimento da autonomia das escolas e melhoria do ensino. Mas a regulamentação do uso dos recursos e o modo de gerir essas políticas nas escolas permanecem sob controle da União.

Em que pese essa contradição, de descentralizar por meio de processos ainda centralizadores, vale destacar, aqui, uma inovação observada nesta pesquisa. O PDDE, como concebido em 1995, leva recursos financeiros diretamente às escolas com base no número de alunos nelas matriculados. O estudo em escolas que não fizeram a adesão ao PDE Escola e ao PME, portanto, que ainda se inscrevem no marco do financiamento direto às escolas criado na década de 1990, mostrou que os recursos recebidos diretamente por meio do PDDE desde 1995 foram acomodados a procedimentos burocráticos, criados nessas escolas para a execução das suas despesas. Tal acomodação passou a dispensar a participação da comunidade escolar nas demandas, que deveriam ser deliberativas, pois elas foram transformadas em rotina e, posteriormente, em expediente para formalizar as prestações de contas das escolas. Assim, se o PDDE de 1995 não chega a estabelecer conflitos no que se refere à tomada de decisões, os novos recursos do PDE Escola e do PME o fazem. Eles são atrelados à implementação de política para melhorar o ensino e ainda não foram acomodados a tal ciclo burocrático interno para a realização das despesas nas escolas.

No caso do PDE Escola e do PME, o recebimento de recursos financeiros está atrelado ao planejamento de práticas para a melhoria do ensino, por meio do planejamento estratégico e da ampliação da jornada escolar na perspectiva da educação integral. Com isso, tais programas do PDE instalam conflitos tanto nos processos escolares internos como entre essas escolas e a gestão da rede de ensino a que se vinculam. Factualmente, instalam algum tipo de mudança.

Neste texto, escolhemos abordar possíveis efeitos da descentralização realizada por meio dos programas PDE Escola e PME na gestão da rede de ensino municipal e em suas escolas. Tal processo é, contraditoriamente, obscurecido no município justamente pela capilarização das ações da União nas escolas. Sob qual prerrogativa legal tais programas da União são implementados diretamente nas escolas? Pensando na gestão das escolas e dos sistemas de ensino dos entes subnacionais, quais as implicações dessa forma de implementar políticas? 


\section{DA UNIÃO DIRETAMENTE ÀS ESCOLAS DOS ESTADOS E DOS MUNICÍPIOS: O CASO DOS PROGRAMAS PDE ESCOLA E MAIS EDUCAÇÃO}

Nesta seção, perscrutaremos a prerrogativa legal sob a qual a União se apoia para implementar os programas PDE Escola e Mais Educação, diretamente, em escolas vinculadas aos sistemas de ensino dos entes federativos subnacionais. A União situa-se no centro de um processo indutor de políticas nas escolas estaduais e municipais. Quais as implicações dessa irradiação de políticas do central para o local?

Um primeiro aspecto importante a considerar no que se refere ao apoio financeiro e material às escolas diz respeito a sua autonomia financeira. Ela é extremamente diversa das autonomias pedagógica e administrativa, por estabelecer uma relação de total dependência com a gestão do sistema de ensino a que se vincula. As escolas não são autônomas em relação aos sistemas de ensino no que se refere à quantidade de recursos necessários para executar seu planejamento. A esse respeito, a pesquisa mostrou que a chegada desse apoio financeiro é a justificativa dos gestores escolares para a adesão aos programas PDE Escola e PME. Portanto, a descentralização desses recursos pode estar suprindo importantes lacunas financeiras nessas escolas.

Longe de qualquer maniqueísmo, lembramos que a descentralização ganhou impulso desde o processo de formulação da CF/1988 e conotação específica no que diz respeito ao financiamento da educação no contexto da Reforma Administrativa do Estado, quando a descentralização das funções administrativas passou a exigir o respectivo aporte financeiro para a manutenção e o custeio das despesas nas escolas, processo do qual derivou a criação do PDDE, em 1995. Após a aprovação da LDBEN de 1996, a rede municipal estudada criou um mecanismo para o repasse de verbas diretamente a suas escolas, em acordo com o artigo 15 dessa LDBEN. Como o PDDE foi utilizado como meio para o financiamento das ações propostas pelo PDE Escola e pelo PME, tal mecanismo para o financiamento é matricial ${ }^{5}$ neste estudo.

É por meio da tensão entre a descentralização e centralização que os recursos do PDDE, PDE Escola e o PME chegam às escolas dos entes federativos subnacionais e são geridos pela União. A descentralização administrativa, aprofundada na década de 1990, já teria sido gestada desde a Assembleia Nacional Constituinte de 1987 (ANC de 1987), quando se buscava, sobretudo,

5 Uso da palavra matricial no sentido de ser esse mecanismo de financiamento uma matriz para a implementação do PDE Escola e do PME. 
descentralizar o sistema tributário nacional e revigorar o sistema federativo (RODRIGUEZ, 2001). Pelo aprofundamento dessa análise, pode-se compreender que, a partir da CF/1988, tornou-se irrefutável a ideia de que a descentralização corresponde ao status quo dos entes federativos subnacionais. Nesse paradigma, a descentralização no sentido da União para os estados e municípios deve observar a autonomia a eles outorgada, sem negligenciar a efetividade do apoio da União para haver condições adequadas para gerir políticas no plano local (ARRETCH, 2011; ALMEIDA, 2005), vez que cabe a ela a função redistributiva e, também, supletiva.

Em contraposição a esse primeiro entendimento, ainda que sob o título de descentralização, há práticas compreendidas como desconcentração, porque são realizadas para o descongestionamento do órgão central. Nelas há delegação de funções do central para o local, objetivando assegurar a eficácia do poder central, em detrimento do apoio da União aos entes federativos subnacionais (OLIVEIRA, 1999; REZENDE, 2005).

A descentralização só ocorre quando há transferência do poder de decisão e autoridade com o objetivo de fortalecer a escola, levando ao controle das atividades da educação pública pelos agentes diretamente envolvidos. Em via oposta, a desconcentração induz as escolas à inobservância da legislação, a equívocos nas prestações de contas e à displicência com a gestão dos seus recursos (REZENDE, 2005), por constituir-se em processo altamente diretivo, por meio de normas externas às instituições locais. Compreende, ainda, o "deslocamento de atribuições do governo nacional para os setores privado e não governamental" (ALMEIDA, 2005, p. 30). Constitui, notoriamente, a diminuição do apoio da União às políticas no plano local e aumento da centralização, por meio de alta diretividade normativa.

O modus operandi da implementação do PDE Escola e do PME hibridiza aspectos dessas duas concepções. Ainda que seja uma prática descentralizadora, efetiva-se de modo contraditoriamente centralizador. Por meio de maior gerência da União, tanto na formulação como na implementação de políticas para o ensino fundamental, emergem ambiguidades que permitem a centralização pela via da descentralização.

Para além da via normativa, o modelo gerencialista subjacente às políticas propostas pelo PDE contribui também para a centralização, pois passou a ser operacionalizado por meio de sistemas informacionais, centralizados na esfera da União. A despeito dessa centralização, cujos efeitos serão abordados a seguir, há uma importante inovação realizada por meio desse recebimento, nas escolas estaduais e municipais, de maior apoio financeiro, material e técnico da União. A pesquisa realizada mostrou, principalmente, que após a adesão das escolas ao 
PDE Escola e ao PME há a criação de uma "pressão intrassistêmica" (PAIVA, 1990, p. 13) por oferta da formação continuada dos profissionais da educação e para a melhoria da infraestrutura das escolas públicas.

Conquanto consideremos esse efeito positivo, cabe lembrar que, desde a CF/1988, o município tornou-se ente federativo autônomo ${ }^{7}$, dotado de autonomia política e financeira, regendo-se por Lei Orgânica promulgada conforme os princípios e preceitos constitucionais ${ }^{8}$. No que concerne à educação, as atribuições e recursos financeiros para o seu desenvolvimento e manutenção por parte dos entes federativos foram estatuídos na CF/1988, nos artigos 211 e 212.

No artigo 211, parágrafo primeiro, pode-se ver que à União compete, também, exercer a função redistributiva e supletiva, de forma a garantir equalização de oportunidades educacionais e padrão mínimo de qualidade do ensino, mediante assistência técnica e financeira aos entes federativos subnacionais. Há uma questão controversa na interpretação e apropriação que o governo federal faz desse aporte legal para legitimar a implementação de ações que desconsideram a estrutura federativa da organização política do território nacional e que repercute para a educação em termos da estrutura do sistema de ensino, consubstanciada na atuação do governo federal diretamente nas escolas dos entes federativos subnacionais.

$\mathrm{Na}$ contramão desse processo, o artigo nono, inciso III, da LDBEN de 1996, estabelece ser atribuição da União: prestar a assistência técnica e financeira para o desenvolvimento dos sistemas de ensino dos Estados, Municípios e do Distrito Federal (BRASIL,1996). Não está prevista, assim, a atuação da União diretamente nas escolas desses entes federativos. Esses institutos definem, inequivocamente, que a atuação da União deve ser realizada para o fortalecimento dos sistemas de ensino, o que não ocorre por meio dessa estratégia proposta no PDE Escola e no PME. No que diz respeito às atribuições do município, factualmente, como houve descentralização nesse processo, seria necessária a institucionalização permanente das condições adequadas para gerir políticas (ARRETCHE, 2011). Esse procedimento ocorre no seio da implementação do PDE Escola e do PME?

$\mathrm{Na}$ pesquisa realizada, foi possível acompanhar a evolução dos sistemas informacionais ${ }^{9}$ desenvolvidos no MEC, após a proposição do PDE,

\footnotetext{
6 Apropriamo-nos dessa expressão criada por Paiva (1990, p. 13) para dizer que a própria política induz a formulação de outras políticas.

7 BRASIL. 1988, Título III, Cap.1, Art.18.

8 BRASIL, 1988, Artigo 29.

9 Na esteira do PDDE e do PDE Escola houve o desenvolvimento do PDE Interativo, que interligou
} 
para o monitoramento das políticas educacionais e prestação de contas dos recursos recebidos diretamente nas escolas. Em que pese esse desenvolvimento informacional na esfera da União, não houve o correspondente apoio para o mesmo desenvolvimento no âmbito do sistema de ensino do município estudado, apesar de ser esta uma atribuição estatuída para a União. Como consequência da complexificação na gestão dessas políticas no município, observamos a desarticulação entre a gestão do sistema de ensino e suas escolas, após a implementação do PDE Escola e PME. Situados em um conjunto mais amplo dos resultados desta pesquisa, destacamos aqui dois efeitos dessa desarticulação no município, relacionados à inadequação infraestrutural, às atividades propostas no PME e à gestão patrimonial.

No primeiro caso, houve o recebimento de equipamentos para um Laboratório de Ciências sem o correspondente local para a realização da atividade. Tal situação teve origem no que foi denominado "subpacto" ${ }^{10}$, levando à frustração do planejamento da escola e, como consequência, pode levar à depreciação do equipamento, tocando diretamente nos aspectos infraestruturais e patrimoniais. Traz à tona, dessa forma, o problema de as escolas não estarem preparadas para ampliar atividades sem a ampliação e adequação dos seus espaços. Ainda que, nessas condições, a política tem o efeito colateral que expressamos anteriormente, por pressão intrassistêmica; neste caso, para a adequação infraestrutural das escolas às exigências da ampliação da jornada escolar regulamentada no artigo 34 da LDBEN de 1996.

O segundo caso está relacionado à aquisição, para atividade do PME, de um equipamento para a produção de vídeo, a ser encaminhado do FNDE a uma das escolas da referida pesquisa. O valor da compra foi computado no total dos recursos programados em 2010 no orçamento do FNDE, não tendo havido, contudo, seu recebimento na instituição escolar. Tal fato ainda não havia sido comunicado, em 2012, nem ao poder público municipal, nem ao FNDE. A escola esperava a atuação da gestão da rede de ensino municipal que, por sua vez, desconhecia o fato, em função da relação direta estabelecida entre a União e suas escolas. Esse evento nos remete à observação da falta de estrutura informacional para gerenciar a capilarização de tais ações da União nas escolas desse sistema

as informações das escolas dos entes federativos subnacionais à base de dados do MEC. Aprofundando-se essa informatização, em 2014 foi implementado o PDDE Interativo.

10 A ação dos programas PDE Escola e PME é desenvolvida nas escolas das redes de ensino dos entes federativos subnacionais após terem firmado o acordo com a União para o desenvolvimento do PAR. Conquanto exista esse acordo entre a União e os Municípios, os programas são implementados em uma relação direta entre as escolas dos entes federativos subnacionais e o MEC; situação que, por ocorrer, no contexto da prática, de forma paralela ao PAR, foi denominada por nós "subpactos" para significar a falta de uma vinculação sistêmica entre o PDE Escola, o PME, o Plano Municipal de Educação e o PAR. 
de ensino municipal, contraditoriamente ao alto padrão de desenvolvimento informacional ocorrido após a proposição do PDE.

Essas ocorrências, escolhidas e restritas ao período de cinco anos, demonstram, portanto, efeitos negativos e em pequena escala da desarticulação entre os níveis de governo, entre os quais incluímos as escolas. Demarcam uma contradição: ocorrem em um contexto de intenso desenvolvimento tecnológico no âmbito da política que, ao propor a melhoria do ensino na escola, negligencia o cumprimento da atribuição da União de fortalecer os sistemas de ensino dos entes federativos subnacionais.

Tal situação exige pensar, também, se tais problemas relativos à accountability (MARQUES, 2013) ocorrem em maior escala entre as esferas de governo e entre a gestão das redes de ensino e suas escolas, mediante observação dos atos e fatos administrativos derivados da ação do FNDE no âmbito dos municípios. Esses efeitos mais amplos servem para colocar em destaque a legislação educacional por parte da União e justificar a necessidade de seu cumprimento.

A autonomia dos entes federativos está relacionada às incumbências de organizar, manter e desenvolver os órgãos e instituições oficiais de seus sistemas de ensino, como se apreende no estabelecido nos artigos de 9 a 11 da LDBEN de 1996. Essas atribuições permitem criar mecanismos para a integração às políticas e planos educacionais da União e dos Estados, passando a definir o tipo de apoio técnico e financeiro demandado à União. No caso do município, a LDBEN de 1996, além de dispor que sejam baixadas normas complementares para seu sistema de ensino, determina a ação redistributiva em relação a suas escolas. Tais institutos e elementos factuais da pesquisa realizada não deixam dúvidas quanto à interpretação e aplicação controversa pela União da legislação educacional e dos efeitos dessa ação na contramão do fortalecimento do sistema de ensino.

Para além dessas relações entre as escolas e a gestão dos sistemas a que se vinculam e entre a gestão local, a regional e a União, há efeitos do PDE Escola e do PME no interior das escolas. Esses programas são implementados diretamente nelas. Assim, importa também discutir aspectos relacionados à cultura dessas instituições, pois ao induzir essa forma de implementar políticas, a União vai, em princípio, na contramão da construção de uma institucionalidade sob a qual se apoiem, para além da gestão democrática, as práticas do autogoverno (BARROSO, 1996), aspecto que será examinado na próxima seção. 


\section{A GESTÃO ESCOLAR E OS PROGRAMAS PDE ESCOLA E MAIS EDUCAÇÃO}

Pensando os efeitos do PDE Escola e do PME, tocamos, desde a seção anterior, em aspectos atinentes à gestão escolar. A ênfase recaiu sobre a dinâmica entre os entes federativos subnacionais e a União e entre as escolas e a gestão dos sistemas de ensino a que se vinculam. Aqui, novamente apoiamo-nos no ponto de confluência entre a União e os Municípios na implementação das políticas estudadas, para chegar a suas implicações nas escolas. O estudo da legislação mostrou que, após a adesão à política da União, sua implementação deve realizarse a partir do ordenamento local.

$\mathrm{Na}$ pesquisa observamos os procedimentos administrativos e financeiros decorrentes do PDE Escola e do PME, concretizados a partir da relação direta entre as escolas da rede municipal e os órgãos do MEC. Ao analisar o modelo operacional e o processo de implementação do PDE Escola e do PME nas escolas, questionamos se a descentralização, como entendida por Arretche (2011) foi sustentada no município por condições adequadas para cumprir a tarefa estatuída para esse ente federativo.

A análise dos documentos das escolas mostrou que, mesmo em um contexto de intensa mudança na dinâmica administrativa, não houve reformulação dos PPPs nas escolas desde 1998. Em decorrência disso, a chegada do PDE Escola e do PME exigiu escolhas que, por sua vez, tocaram nesse aspecto, tanto no sentido de impulsionar a reformulação dessa política da escola como de trazer à tona fragilidades pedagógicas, uma e outras profundamente ligadas ao objetivo do PDE e ao princípio constitucional sob o qual a educação escolar deve ser organizada: a garantia do padrão de qualidade do ensino.

Após a aprovação da LDBEN de 1996 houve a necessidade de adequação dos sistemas de ensino municipais e estaduais às novas regras, assim como das escolas à descentralização das funções administrativas, aos procedimentos decorrentes do repasse dos recursos financeiros da União, bem como das relações entre os sistemas de ensino e as escolas, mediante as regras criadas para orientar a autonomia pedagógica no interior de um mesmo sistema de ensino.

O conceito de autonomia relaciona-se ao que Barroso (1996, p. 17) denomina autogoverno, na medida em que os atores sociais de uma instituição criam suas regras e se orientam por elas. Entretanto, "a autonomia é um conceito relacional", porque, como sujeitos, exercem suas ações sempre "num contexto de interdependência e num sistema de relações", havendo também "variações quanto a sua intensidade, pode-se ser mais ou menos autônomos em relação a determinadas ações". 
A LDBEN de 1996, ao estabelecer no seu artigo 15, que os sistemas de ensino assegurem às escolas públicas de educação básica progressivos graus de autonomia pedagógica, administrativa e de gestão financeira, observadas as normas do direito financeiro público, consolida essa ideia de que a autonomia das escolas é realizada numa relação de dependência com o sistema de ensino ao qual estas estão vinculadas. Assim, a despeito de as escolas públicas serem autônomas para construir seus projetos educacionais e seu regulamento interno, como instituições públicas, são subordinadas às regras dos sistemas de ensino e à legislação federal.

Nesse mesmo paradigma é que a participação dos profissionais da educação, princípio fundamental da gestão democrática, foi ordenada na LDBEN de 1996, no seu artigo 14, no sentido da sua exigência no processo de construção da proposta educacional das escolas, a partir da qual as escolas se autogovernam e orientam as suas dependências através de suas próprias leis (BRASII, 1996). No caso específico da adesão e implementação de políticas externas, é a consolidação da autonomia escolar construída em um processo de gestão democrática que torna hegemônica a proposta educacional da escola. Caso contrário, ocorre a implantação de políticas na escola, ou perda de oportunidades de se gerirem dependências a favor da escola pública.

Essa participação é fundamental para o aprofundamento de uma cultura da escola afinada com a proteção dos direitos educacionais, devendo estar subjacente à construção e reconstrução permanente da proposta educacional de cada escola. Contudo, ainda que considerando as culturas das escolas (FORQUIN, 1993), a pesquisa mostrou que $75 \%$ delas não tinham os projetos político pedagógicos (PPP) atualizados. Desse conjunto, apenas uma escola passou, após 2010 e a adesão ao PDE Escola, a tomar esse processo de reconstrução como prática. Pelo fato de essa escola ter uma cultura participativa, houve a escolha da reelaboração do PPP como uma meta do PDE Escola, o que mostrou a apropriação da política da União pela cultura da escola. As entrevistas com os educadores das outras escolas mostraram a possibilidade de que, mesmo ante a intenção de reconstruir essa proposta sem o apoio da gestão da rede de ensino, pode não ocorrer por falta de espaço/tempo apropriado para essa ação, que demanda o envolvimento de todos os profissionais.

Naquela escola que optou pela reelaboração do PPP, mesmo após o final da vigência do PDE Escola em 2012, o mesmo procedimento foi realizado: sinal de uma possível mudança. Já no que se refere ao PME, as atividades desse programa coincidiram com as já praticadas nas escolas. Tal situação foi generalizada para as escolas da rede de ensino municipal que fizeram adesão ao PME. Nelas, a adesão foi realizada como forma de captar recursos para melhorar tais atividades. 
O estudo mostrou ser a implementação do PME mais sinuosa do que a do PDE Escola, sobre o qual o diretor de uma das escolas relatou: "vem tudo pronto, é só executar". Nesse caso, o PDE Escola apontou que, para a melhoria da gestão escolar, seria necessária a formulação, participativa, da proposta educacional da escola. Conquanto apoiar essa iniciativa seja o papel da gestão da rede de ensino no município, esta pesquisa observou a ausência desse apoio específico após 1998.

No que se refere à gestão financeira, a análise das despesas para a manutenção das escolas no município mostrou não haver vínculos entre a proposta educacional das escolas e a liberação de recursos financeiros para elas pelo órgão municipal de educação. Tal fato desprestigia o exercício de construção do PPP nas escolas, porque sinaliza uma compreensão de que a ausência dessa proposta não traz consequências concretas. Por esse motivo, atrelar o recebimento de recursos financeiros e outros recursos necessários à execução de um planejamento formulado pela escola para a melhoria de suas ações e a partir de suas culturas - pode ser um caminho para criar experiências participativas exitosas e um planejamento sistêmico, que induza ao próprio cumprimento dos princípios constitucionais da gestão democrática e da garantia do padrão de qualidade.

$\mathrm{Na}$ tradição burocrática das escolas e da rede de ensino estudada, como os recursos financeiros não são vinculados à execução do PPP, o financiamento e o planejamento pedagógico são separados desde a origem do processo. Este estudo mostrou que, apesar de o PDE Escola inovar nessa direção, ainda não há uma reflexão por parte dos profissionais da educação sobre os aspectos positivos desse atrelamento do financiamento ao PPP.

No período que antecedeu à proposição do PDE Escola e do PME, os dados da rede de ensino estudada mostraram que as escolas já desenvolviam atividades "extracurriculares", com a ampliação da jornada escolar por meio de projetos, sem, contudo, receberem verbas específicas para sua manutenção. Em função das necessidades dos projetos, as escolas e a gestão da rede de ensino não problematizaram os aspectos mais amplos dessa política, que tende à centralização das diretrizes para as ações na esfera da União, em detrimento do apoio ao fortalecimento dos sistemas de ensino.

Observamos, nas duas escolas que não fizeram adesão ao PDE Escola e ao PME, a definição das atividades para todo o período letivo sem a participação dos professores, ficando o planejamento e a condução das reuniões pedagógicas sob encargo da coordenação, com uma pauta restrita a questões administrativas. Considerando as experiências na gestão das escolas que fizeram adesão a essas duas políticas, observamos que o PDE Escola e o PME têm o efeito de desafiar a construção de práticas novas, demandando a participação para a superação dos problemas. 
Também foi possível verificar a necessidade de apoio financeiro para o desenvolvimento dos projetos como justificativa generalizada para a adesão ao PDE Escola e ao PME, por parte das escolas e da gestão da rede de ensino. Portanto, houve essa adesão à política externa como possibilidade para a solução imediata dos problemas "crônicos" das escolas, tal como ocorreu no processo de implementação do PDE/Fundescola (FONSECA; OLIVEIRA, 2003; FONSECA; TOSCHI; OLIVEIRA, 2004). Pode-se ver que, em geral, mantêmse alguns dos problemas das escolas desde a proposição da política do Fundescola em 1998, o que atualiza sua classificação como crônicos.

A análise dos documentos (instrumentos) do PDE Escola mostrou, em uma das escolas da pesquisa, que o grupo de trabalho que atuou no diagnóstico para a formulação do Plano induziu uma valoração maior do que a real dos itens referentes à infraestrutura, ainda que tenha havido a necessidade de priorizar ações que melhorassem a organização pedagógica. Nessa instituição, foi identificada, nos documentos de diagnóstico do PDE Escola, a necessidade de planejamento das ações para superar: o baixo desempenho, o currículo desorganizado e desarticulado, a alta taxa de distorção idade/série (DIS), a falta de estratégias de ensino diferenciadas e, também, a necessidade de melhoria da infraestrutura.

Pela valoração que os profissionais da educação deram aos itens do diagnóstico é que foram delimitadas as ações financiáveis e não financiáveis. A análise do PDE Escola (instrumentos) mostrou que, aproximadamente, 70\% dos recursos financeiros foram destinados à aquisição de materiais didáticopedagógicos. Assim, as outras ações, com objetivos que incidem diretamente na prática de ensino e na aprendizagem tornaram-se ações não financiáveis.

Pudemos verificar, no diagnóstico realizado para a elaboração do Plano de Ações Financiáveis do PDE Escola nessa instituição, importantes contradições, percebidas somente após a implementação do programa. A principal delas consiste no diagnóstico ${ }^{11}$ de que os professores conhecem metodologias de avaliação e usam esse conhecimento (escala 4), de que demonstram ter domínio da matéria que ensinam (escala 5), de que a direção da escola define um programa de formação para os docentes (escala 3). Contudo, após a implementação, não só do PDE Escola, mas também do PME, a direção da escola analisou a conjuntura e relatou o que aprendera nesse processo:

Temos armários cheios de jogos que os professores sugeriram, compramos também os armários, mas o uso é muito restrito, poucos professores usaram. Eu não conhecia os materiais dourados, atuo nas séries finais do ensino fundamental, não tenho essa formação, mas pensava que os professores das séries iniciais deveriam conhecer e soubessem usar. Eu não sabia que os professores não sabiam 
usar esses materiais, (...) Os armários estão abertos, tudo que queríamos era que fossem usados. (Entrevista com gestor de escola pública municipal que aderiu ao PDE Escola e ao PME, 2012).

Essa exposição da fragilidade na formação dos professores contradiz o diagnóstico realizado coletivamente e consolidado como instrumento do PDE Escola. Mostra o desconhecimento, da gestão escolar, das necessidades de formação dos professores. O documento, dessa instituição, "Instrumento: diagnóstico" do PDE Escola, informa que todos os professores têm domínio dos conteúdos por eles ensinados. Por isso, o Plano de ações financiáveis do PDE Escola dirigiu a maior parte dos recursos para a aquisição de materiais pedagógicos e melhoria da infraestrutura.

Com a convergência, verificada nas escolas da pesquisa, entre a implementação do PDE Escola e do PME, essa fragilidade da formação dos professores tornou-se notória. Isso porque, com os materiais adquiridos e a definição de sua utilização entre as ações do PME, foi identificado que os professores precisariam familiarizar-se com sua incorporação às atividades pedagógicas. Essa situação levou à criação de Grupos de Estudos no âmbito da secretaria municipal de educação (SE), demandada pelos profissionais. Virtude do PME que estimula professores a ampliarem suas oportunidades de formação e de melhoria da qualidade do ensino.

Tal demanda formativa, já latente, tende à ampliação, tendo em vista a progressiva oferta da educação integral instituída na LDBEN de 1996 e no Plano Nacional de Educação (PNE) de 2014 e o fato de que, até dezembro de 2012, as ações do PME atenderam somente $20 \%$ dos alunos matriculados na rede de ensino. Além dos Grupos de Estudos sobre práticas pedagógicas, serão necessárias oportunidades de formação sobre educação integral e gestão intersetorial. Como a política do Estado respalda a compreensão de que as escolas deverão oferecer a educação em tempo integral para todos os alunos, é possível inferir que deverá haver aumento dessa demanda formativa em face do aumento do número de professores que, em tese, acompanharia a progressão do atendimento aos $80 \%$ dos alunos que ainda não estão incluídos nas atividades da jornada escolar ampliada. Nesse sentido, há que ser considerada a atuação mais forte da União, junto aos entes federativos subnacionais, para a oferta de formação adequada aos professores que lidarão com essa realidade.

O processo de adesão ao PME é mais denso, dinâmico e complexo do que suposto pelos profissionais que atuam nas escolas e na gestão da rede de ensino municipal. Se à ampliação do tempo acompanhar uma concepção de educação integral, pode-se compreender, de fato, a possibilidade de se caminhar na perspectiva da garantia do padrão de qualidade (CAVALIERE, 2009; COELHO, 
1997; MENEZES, 2012). A estratégia proposta por meio do PME pode avançar no sentido da proteção do direito à garantia do padrão de qualidade, não somente pela possibilidade dos recursos recebidos nas escolas, mas, principalmente, por propor a educação integral como um dos seus princípios basilares.

Por tal princípio, foi importante conhecer os desafios na implementação dessas políticas. As observações no cotidiano escolar, as análises documentais e dos dados e as entrevistas concedidas por profissionais do ensino nas escolas e na SE mostraram as dificuldades enfrentadas no primeiro momento de adesão ao PME. Contudo, a partir das experiências para o atendimento a demandas individuais para a formação dos professores e dos gestores, foram criadas ações formativas, extrapolando a própria capacidade de ação da gestão da rede de ensino estudada. Equivale a dizer que, também nesse aspecto, a política externa influenciou a mudança.

As atividades desenvolvidas pelo PME trouxeram oportunidades novas para alunos e professores. Por isso, a condição em que se realizam as atividades "extracurriculares" nas escolas que não fizeram adesão ao PME passou a ser percebida como aspecto negativo mediante o princípio da igualdade do acesso e permanência na escola (BRASIL, CF/1988, artigo 206), sob o qual o ensino deve ser organizado. Tal aspecto denota uma possível mudança no que diz respeito à exigência das escolas por essa igualdade de oportunidades.

De certo modo, a virtude do PME relaciona-se, ambiguamente, aos desafios que emergem do modo como esta política interpela o cotidiano, a gestão da rede de ensino, o Sistema Municipal de Ensino e as ações decorrentes do pacto federativo. No que se refere à formação dos professores, a gestão da rede de ensino atuou na competência da União sem acionar os setores adequados para induzir uma formação em regime de cooperação. Esse fato ocorreu em função do próprio tempo para a implementação do PME e para a ação por parte da gestão da rede de ensino municipal.

Tal experiência foi considerada inovadora por unir os atores educacionais sob o objetivo comum de construir ações que induzam o aprimoramento das práticas docentes e de gestão escolar, para a melhoria do ensino. Contudo, o PME, como um caminho para a melhoria do padrão de qualidade do ensino e proteção dos direitos dos alunos, depende, para alcançar esse objetivo, de um esforço maior da União e da gestão da rede de ensino no município estudado. Como se trata da tendência de universalização dessa política, deve-se também reformular pactos para atuar em regime de cooperação com a União nas ações formativas e infraestruturais.

No que se refere à relação entre a formação dos profissionais da educação escolar, as atividades e os princípios do PME, há exigência de estudos sobre a 
integração entre os conteúdos das disciplinas curriculares e as atividades realizadas no contraturno das instituições educacionais. Além disso, há desafios na oferta de suas ações em articulação com as culturas dessas instituições para influenciar as vivências dos professores e dos alunos e, assim, melhorar a qualidade do ensino e da aprendizagem. Transpor esses desafios contribui para mudar a cultura escolar (FORQUIN, 1993), no que se refere à ampliação das oportunidades das vivências que contribuam para a desnaturalização das condições degradáveis da existência bumana, à medida que as mudanças se direcionarem à inclusão dos alunos que, ainda que dentro da escola, estão à margem dessa educação por estarem à margem da cultura escolar. Tal focalização, nesse contexto, não prescinde da democratização de todas as atividades, mas demarca o patamar atual de lutas para avanços em termos da proteção do direito à educação escolar, aqui estreitamente ligada aos direitos humanos.

\section{CONCLUSÕES OU CONSIDERAÇÕES FINAIS}

A despeito de considerarmos extremamente positivo o fato de a União atuar de forma mais ativa no que concerne ao apoio técnico e financeiro às escolas públicas vinculadas aos estados, aos municípios e ao distrito federal, a ação realizada por meio do PDE Escola e do PME traz à tona sua problematização ante o federalismo como princípio constitutivo da república brasileira, uma vez que tal processo de descentralização financeira desconsidera a organização política e administrativa do território nacional, podendo produzir consequências no que se refere à própria organização dos sistemas de ensino locais.

Neste estudo, vinculamos a melhoria da qualidade à criação de novas oportunidades para a vivência de experiências escolares exitosas, não somente no sentido da apropriação do conhecimento historicamente construído pela humanidade, mas também de compartilhamento de vivências bumanas (CAVALIERE, 2009) contraditórias ao ciclo de naturalização das condiçoes bumanamente degradantes (MAGRONE, 2008) a que estão sujeitos muitos alunos das escolas públicas municipais da rede de ensino estudada. A partir dessa opção ética, que também é metodológica, foi possível perceber que o PDE Escola e o PME trazem apoio às escolas para a criação dessas novas oportunidades para os alunos.

Conquanto seja positiva essa inovação, este estudo possibilitou compreender, no contexto da prática, desafios e limites que vêm desde a estrutura que antecede a proposição do PDE Escola e do PME até a realidade em que os programas são implementados. A "adesão de fato" aos princípios das duas políticas não ocorreu; os programas foram interpretados e reinterpretados de modo a serem adaptados até a conformação às culturas das escolas (FORQUIN, 
1993). Além disso, o tempo com o qual o poder público local e as comunidades escolares tentam lidar com as novas práticas não foi suficiente para acompanhar o tempo da política proposta pela União.

A mudança mais ampla está a exigir a criação de uma direção contrária a essa lógica atual, passando os governos locais a atuarem mais no processo de formulação das políticas educacionais na esfera da União. Tal afirmação encontra apoio no fato de que a posse das informações sobre os sistemas de ensino contribui para que a União induza, fortemente, políticas para o ensino fundamental sem a participação dos governos locais em sua formulação. A despeito do sistema representativo vigente na democracia brasileira, sem essa participação, o planejamento educacional no âmbito da União pode ficar restrito ao nível dos técnicos da União.

De outro lado, a adesão imediata a essas políticas no município pode tornar-se um modo de preencher a lacuna tanto da inércia do planejamento local quanto da suposta escassez de recursos nas escolas. Do preenchimento de uma lacuna a outra, dá-se a adesão ampla à política do Estado (Ferreira e Fonseca, 2013, p. 287) sem, contudo, haver uma participação correspondente. Não há demonstrações de que o PDE Escola e o PME resultaram em melhoria da qualidade do ensino fundamental. Por isso, não há possibilidade de se atribuir a esses programas possíveis melhorias, em função da diversidade de fatores que influenciam os resultados dos alunos nas escolas.

De imediato, essas políticas trazem a possibilidade de convivência com melhores condições formativas, materiais organizacionais e o impulso para um novo ciclo de pressão intrassistêmica. Dessa feita, podem induzir melhoria infraestrutural, novas expectativas quanto às práticas docentes, às aprendizagens dos alunos e à participação intensa na consolidação de uma direção ética e política, desde a cultura das escolas até a proposição de medidas que deem efetividade a seus projetos educacionais. A partilha desse processo nas escolas - entre todos os alunos e em condições de igualdade - seria o passo posterior a ser impulsionado por essa pressão. A chegada a esse patamar significaria termos avançado no sentido de melhorias na proteção dos direitos de cidadania, exigência maior a toda proposta que objetive melhorar a qualidade do ensino nas escolas públicas.

\section{REFERENNCIAS}

ALMEIDA, M. H. T. de. Recentralizando a federação? Revista Sociologia e Política. Curitiba, n.24, p. 29-39, jun. 2005. Dossiê Federalismo.

ARRETCHE, M. Estado federativo e políticas sociais: determinantes da 
descentralização. Rio de Janeiro: Revan; São Paulo: FAPESP, 2000, $3^{a}$ ed., agosto de 2011.

BARROSO, J. O estudo da autonomia da escola: da autonomia decretada à autonomia construída. In: BARROSO, J.(org). O estudo da escola. Porto: Porto Editora, 1996, p. 167-189.

BRASIL. Constituição Federal de 1988. Texto Constitucional, de 05 de outubro de 1988. Disponível em < www.planalto.gov.br> Acesso em: 03/12/2013

Lei $\mathbf{n}^{\mathbf{0}} \mathbf{9 . 3 9 4}$, de 20 de dezembro de 1996. Estabelece as diretrizes e bases da educação nacional. Diário Oficial da República Federativa do Brasil, Brasília, 23 de dezembro de 1996. Disponível em : < http://www.planalto.gov. br> Acesso em: 26/06/2003

Decreto ${ }^{\circ} \mathbf{6 . 0 9 4}$, de 24 de abril de 2007a. Dispõe sobre a implementação do Plano de Metas Compromisso Todos pela Educação. Disponível em: < http:/ / www.planalto.gov.br> Acesso em: 05/01/2009.

Portaria Normativa Interministerial $\mathrm{n}^{\circ}$ 17, de 24 de abril de 2007b. Institui o Programa Mais Educação. Disponível em : < portal.mec.gov.br/index. php?option=com_docman\&task $>$ Acesso em: 21/06/2008

MEC. Portaria Normativa $\mathbf{n}^{\circ}$ 27, de 21 de junho de 2007c. Institui o Plano de Desenvolvimento da Escola - PDE Escola. Disponível em : < portal. mec.gov.br/index.php?option=com_docman\&task $>$ Acesso em: 21/06/2008

Resolução/CD/FNDE no 19, de 15 de maio de 2008. Dispõe sobre a adesão, habilitação e as formas de execução e prestação de contas referentes noPDDE. Disponível em: <http://www.fnde.gov.br/> Acesso em: 22/09/2009.

Decreto $\mathbf{n}^{\mathbf{0}} \mathbf{7 . 0 8 3}$, de 27 de janeiro de 2010. Dispõe sobre o Programa Mais Educação. Disponível em: <http://www.planalto.gov.br/ccivil_03/_ ato2007 2010/2010/decreto/d7083.htm> Acesso em: 29/09/2010.

CAVALIERE, A. M. V. Escolas de tempo integral versus alunos em tempo integral. Em Aberto, Brasília, v.22, n. 80, p.51-63, abr. 2009.

COElho, L. M. C. da C. Escola pública de horário integral. Presença 
Pedagógica, v. 3, n. 15, p. 53-59, maio/jun. 1997.

FERREIRA, E. B, FONSECA, M. Plano de Ações Articuladas (PAR): discutindo dados da pesquisa em rede. In: FONSECA, M.; FERREIRA, E. B. (Orgs.) Política e planejamento educacional no Brasil do século 21. Brasília: Liber Livro, 2013, p. 281-298.

FONSECA, M., OLIVEIRA, J. O Plano de Desenvolvimento da Escola (PDE): modernização, diretividade e controle da gestão e do trabalho escolar. $\mathbf{2 6}^{\mathbf{a}}$ Reunião Anual da ANPEd. Caxambu, 2003.Disponível em: <http:/ /26reuniao. anped.org.br/trabalhos/05tmarfo.pdf> Acesso em: 25/03/2010.

. TOSCHI, M. S., OLIVEIRA, J. F.. (Orgs) Escolas gerenciadas: planos de desenvolvimento e projetos político-pedagógicos em debate. Goiânia: Ed. da UCG, 2004.

FORQUIN, J. C. Escola e Cultura: as bases sociais e epistemológicas do conhecimento escolar. Tradução de Guacira Lopes Louro. Porto Alegre: Artes Médicas, 1993.

JUIZ DE FORA, Portaria 2.317 de 1995, dispõe sobre o Programa Nossa Escola. Juiz de Fora: Secretaria Municipal de Educação, 1995.

MAGRONE, E. Entrevista: Precariedade das escolas estaduais de Minas Gerais. Jornal Tribuna de Minas, 06/05/2008, p.3, Juiz de Fora, MG.

MARQUES, F. G. Accountability. In: DI GIOVANNI, Geraldo; NOGUEIRA, Marco Aurélio: Dicionário de Políticas Públicas. São Paulo: FUNDAP: Imprensa Oficial do Estado de São Paulo, 2013, p. 55-56.

MENEZES, J. S. S. Educação em tempo integral: direito e Financiamento. Educar em Revista, Curitiba, Brasil, n. 45, p. 137-152, jul./set. 2012. Editora: UFPR

OLIVEIRA, C. et al. Municipalização do ensino no Brasil. Belo Horizonte: Autêntica, 1999.

OliveIRA, R. C.. Programas PDE Escola e Mais Educação: descentralização e gestão do ensino. 2014, 354 p. Tese (Doutorado em Educação) - Universidade Federal de Juiz de Fora, 2014. 
PAIVA, V. P. Um século de educação republicana. Pro-Posições. Campinas: UNICAMP; Cortez, n.2, p. 7-18, jul 1990.

REZENDE, V. M.. Descentralização ou desconcentração? $O$ controle dos gastos com a educação: ação que supera a autonomia da escola. $\mathbf{2 8}^{\mathbf{a}}$ Reunião da ANPEd, 2005. Disponível em: <http://28reuniao.anped.org.br/gt05.htm>. Acesso em: 25/03/2010.

RODRIGUEZ, V. Financiamento da Educação e Políticas Públicas: o FUNDEF e a política de descentralização. Cadernos Cedes, ano XXI, no 55 42-57, novembro/2001.

RITA DE CÁSSIA OLIVEIRA é doutora em Educação pela Universidade Federal de Juiz de Fora (UFJF). Professora efetiva na rede municipal de Juiz de Fora, com atuação na gestão do sistema de ensino local e no ensino fundamental. E-mail: ritadgf@yahoo.com.br

BEATRIZ DE BASTO TEIXEIRA é doutora em educação pela Universidade de São Paulo (USP). Professora Associada da Universidade Federal de Juiz de Fora (UFJF), com atuação no Departamento de Ciências Sociais, no Programa de Pós-graduação em Educação e no Mestrado Profissional em Gestão e Avaliação da Educação Pública. E-mail: beatriz.teixeira@ufff.edu.br.

Recebido em fevereiro de 2015

Aprovado em setembro de 2015 